\title{
Quartz exposures and severe silicosis: a role for the hilar nodes
}

\author{
Anthony Seaton, John W Cherrie
}

Department of Environmental and Occupational Medicine, University of Aberdeen Medical School, Aberdeen, Scotland

A Seaton

J W Cherrie

Correspondence to: Professor A Seaton, Department of Environmental and Occupational Medicine, University of Aberdeen

Medical School, Foresterhill, Aberdeen AB25 2ZD, Scotland, UK

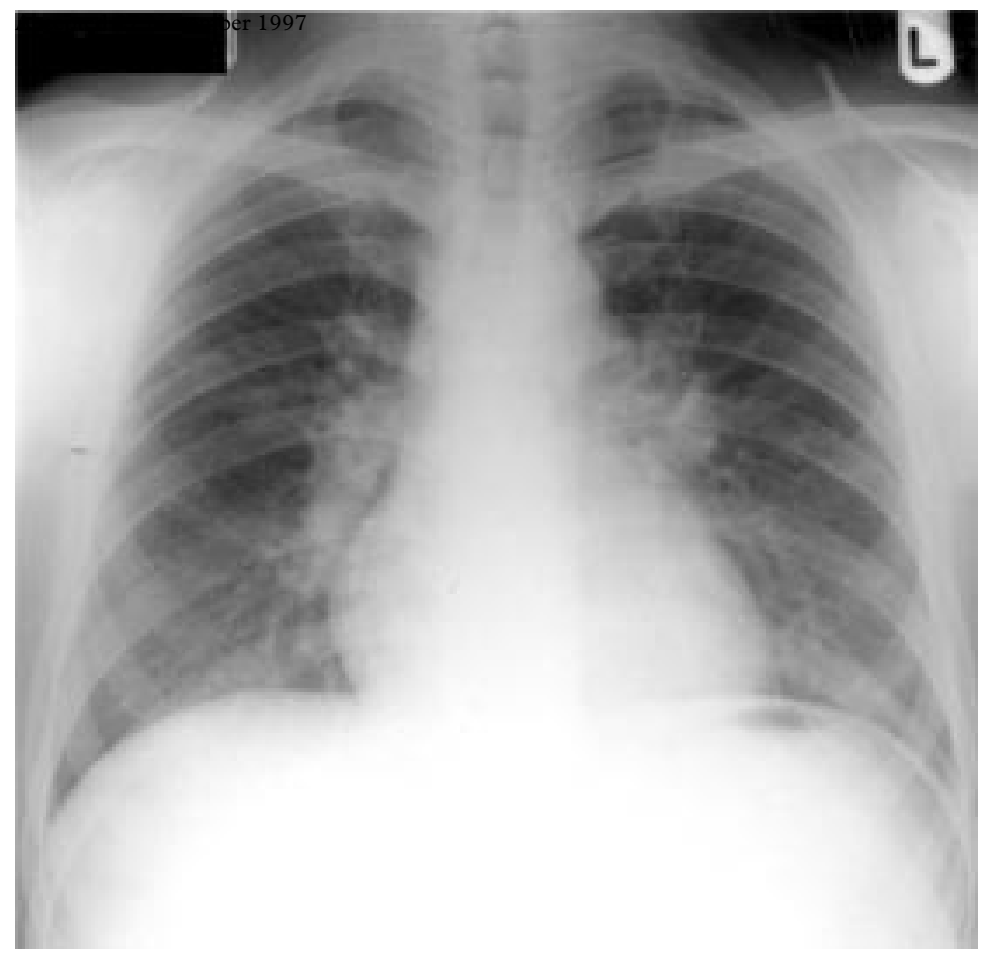
histories, and semiquantitative exposure modelling.

Results-One of the men who died had a 30 year exposure estimated to have averaged $<0.1 \mathrm{mg} / \mathrm{m}^{3}$, leading to hilar node fibrosis and calcification, followed by a five year exposure to about $2 \mathrm{mg} / \mathrm{m}^{3}$ which proved fatal. Estimates of exposure tallied with postmortem measurement of lung burden, suggesting retention of all dust deposited in the lungs over his final period of work. The younger man, working from the start of his apprenticeship alongside the older one, had a six year exposure to about $1.5 \mathrm{mg} / \mathrm{m}^{3}$, which caused hilar node

\begin{abstract}
Background-Two stonemasons working together in an environment with high concentrations of quartz pursued very different clinical courses; one died of rapidly progressive silicosis and the other developed hilar adenopathy and, later, early massive fibrosis. The exposures to quartz of these two men were investigated to allow comment on the pathogenesis of severe silicosis relative to concentrations of dust.

Methods-Estimates of exposure were based on previously taken personal dust

enlargement and subsequent calcification but minimal lung involvement.

Conclusions-Exposures to relatively low concentrations of quartz may be capable of causing hilar node fibrosis, impairing the clearance of any quartz inhaled subsequently. The findings support the concept that destruction of the hilar nodes by silicotic fibrosis, impairing lung clearance, has an important pathogenic role in the development of massive fibrosis, and in men subsequently exposed to very high concentrations of respirable quartz, rapidly progessive silicosis.
\end{abstract} samples, detailed lifetime occupational

Figure 11990 Chest radiograph of patient 1, showing bilateral hilar lymphadenopathy.

\section{(Occup Environ Med 1998;55:383-386)}

Keywords: quartz; silicosis; hilar nodes

In 1989 we investigated an outbreak of silicosis among eight stonemasons working with sandstone on a Scottish mediaeval cathedral. Two had died of acute silicosis and three others had radiographic changes of classic silicosis; one had early massive fibrosis. ${ }^{1}$ A sixth was found to have bilateral hilar lymphadenopathy, ascribed at the time to probable sarcoidosis. The outcome of the man with hilar adenopathy and estimates of the quartz exposures that led to the disease in two of these men are reported.

\section{Case reports}

Patient 1 , a healthy 25 year old man, was seen in the chest clinic in 1989 because an abnormal chest radiograph had been found on a survey at his workplace. He had started work as a stonemason on the cathedral in 1980 at the age of 16 , for the first year with traditional hand tools and thereafter pneumatic saws, chisels, and buffers for five hours daily, sweeping up after work, five days a week. No exhaust ventilation had been provided, but for all except his first year he had used an airstream type helmet respirator.

His chest radiograph (fig 1) showed marked bilateral hilar lymphadenopathy but no intrapulmonary disease. Lung function showed minimal airflow obstruction. A provisional diagnosis of sarcoidosis was made, but a Kveim test was negative. He was followed up as an outpatient and in late 1990 it was noted that he had some infiltration at the left apex. Subsequent films and computed tomography showed small areas of irregular fibrosis at both apices consistent with early massive fibrosis, with enlarged hilar nodes and eggshell calcification. Lung function showed some reduction in lung volumes and diffusing capacity. 
The clinical course of patient 2 has been reported previously (case 1 , Seaton et $a l^{1}$ ) $\mathrm{He}$ had worked with hand tools on granite from 1948 until 1978 and had then worked alongside patient 1 until 1984 . He wore his respirator less often than the younger man. A chest film taken in 1980 had shown no silicosis but in 1984 eggshell calcification of the hilar nodes was present as well as signs of accelerated silicosis. He died aged 54 from respiratory failure due to rapidly progressive silicosis. At necropsy his lung showed the extremely high quartz content of $21 \mathrm{mg} / \mathrm{g}$ dry tissue.

\section{Methods}

We obtained detailed lifelong occupational histories from both men. Exposures were estimated based on these histories, knowledge of respirator use, and measurements made periodically in the workplace.

The work involved cutting and shaping sandstone for the cathedral windows. The sandstone contained $98 \%$ quartz. It was first cut into blocks by a diamond tipped saw and then dressed by the masons in an open sided shed. The work was detailed, requiring the masons' faces to be within $30 \mathrm{~cm}$ of the stone;
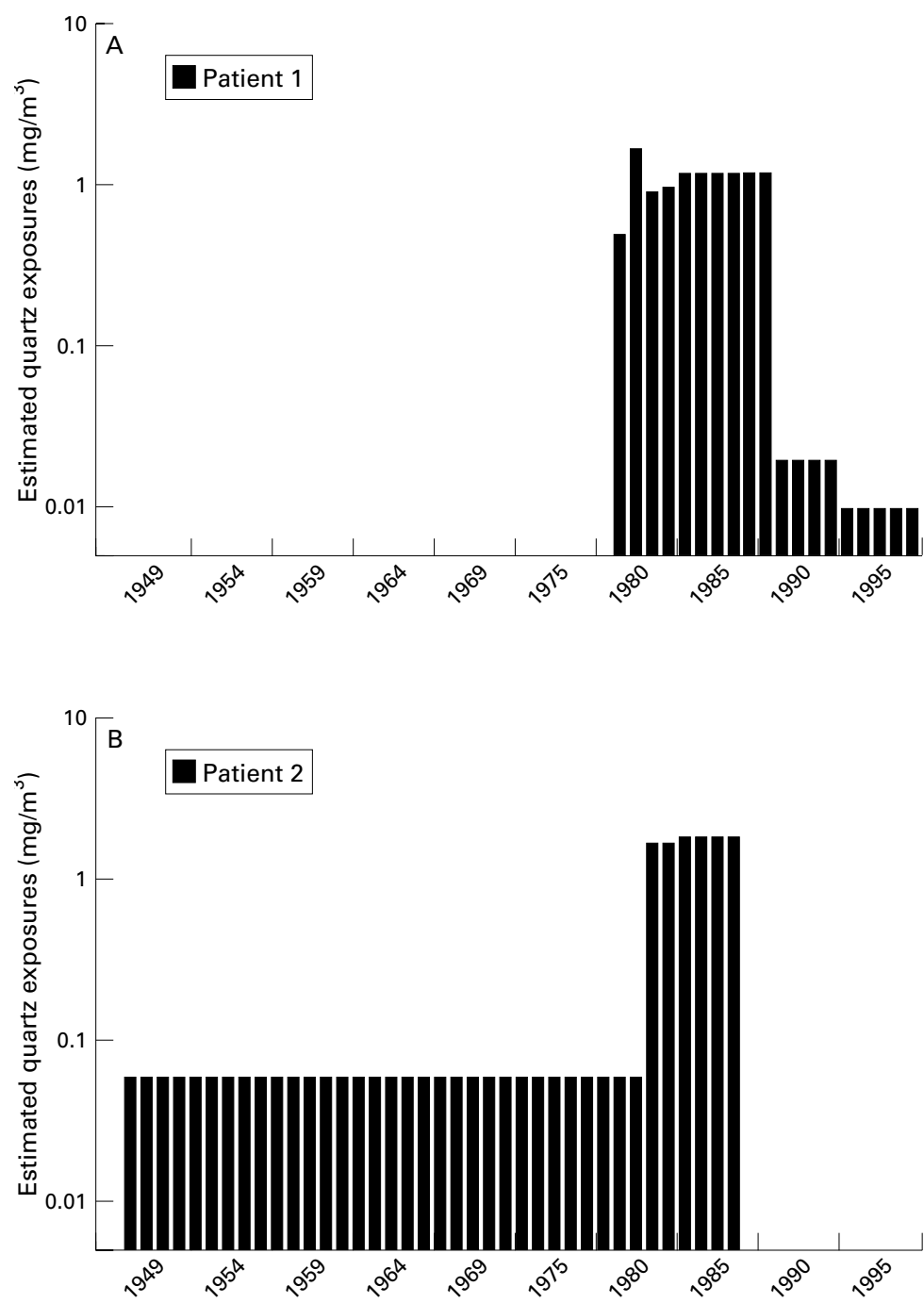

Figure 2 Estimated lifetime respirable quartz exposures of patients 1 and 2. no significant variations in working practices occurred over the years 1978 to 1989 . The helmets were in poor repair and the visors often had to be lifted to see the job. After our investigation a local exhaust ventilation system was installed and new, more efficient, helmet respirators were purchased.

Dust concentrations had been measured periodically at the lapel of the masons. Air was drawn by a Casella 123 personal sampling pump at $1.9 \mathrm{l} / \mathrm{min}$ through $37 \mathrm{~mm}$ diameter Gelman VM1 filters located inside Casella cyclones. After our involvement, we made measurements simultaneously inside and outside the respirator visor. We have adjusted our exposure estimates to correspond roughly with the methods currently recommended by the United Kingdom Health and Safety Executive (HSE). ${ }^{2}$

The exposure concentrations during unmeasured periods were estimated with methods developed for an epidemiological study of workers on manmade mineral fibres. ${ }^{3}$ This approach uses a series of multiplicative modifying factors to adjust the levels of exposure for changes in the intrinsic dustiness of the stone being worked, the method of working the stone, the effectiveness of local ventilation, the duration of the work, and the effectiveness of the respiratory protection in each of the tasks they undertook. The men's work histories were divided into several periods corresponding to significant changes in their activities, and the exposure concentration was reconstructed for each period.

\section{Results}

Measured exposures, excluding any reduction resulting from the use of respirators, ranged from $8 \mathrm{mg} / \mathrm{m}^{3}$ respirable quartz during the first survey when there was no local ventilation to generally $<0.5 \mathrm{mg} / \mathrm{m}^{3}$ after the ventilation had been installed. The exposure concentrations for the apprentice stonemasons were generally lower than those for the masons because the apprentice stonemasons generally used hand rather than powered tools. Measurements made of exposures inside a high efficiency airstream powered helmet respirator showed reduction of dust concentrations by about 30 -fold while the respirator was being worn continuously. Assuming a protection factor of 10 from regular use of the previous relatively inefficient and poorly maintained respirator, the wearers' actual daily exposures to respirable quartz were estimated to have been of the order of $1 \mathrm{mg} / \mathrm{m}^{3}$.

From these measurements and the occupational histories it has been possible to estimate lifetime respirable dust exposure for these subjects (fig 2). During his previous employment, patient 2 would have been exposed to low quartz concentrations (estimated to have averaged $0.06 \mathrm{mg} / \mathrm{m}^{3}$ ), because of the lower quartz content and dustiness of granite and the use of hammer and chisel rather than power tools. During the period from about 1982 to 1987 both men had closely similar exposures, but because patient 1 reported that he regularly used his respirator we have assigned a slightly 
lower exposure for him $\left(1.5 \mathrm{mg} / \mathrm{m}^{3}\right.$ as opposed to $2.1 \mathrm{mg} / \mathrm{m}^{3}$ ). After the introduction of the local ventilation and the more efficient respirators the actual concentration of quartz inhaled by patient 1 is likely to have been very low (about $0.03 \mathrm{mg} / \mathrm{m}^{3}$ ).

Cumulative exposure to respirable quartz for patient 1 has been estimated as $12 \mathrm{mg} / \mathrm{m}^{3}$.y, of which about $99 \%$ occurred before 1990 when the controls were introduced. This corresponds to an average concentration of exposure throughout his employment of $0.7 \mathrm{mg} / \mathrm{m}^{3}$. Patient 2 had a very similar cumulative quartz exposure $\left(13 \mathrm{mg} / \mathrm{m}^{3} . \mathrm{y}\right)$, with about $16 \%$ of this arising from his previous employment as a granite stonemason. His average exposure throughout his working life was estimated as $0.3 \mathrm{mg} / \mathrm{m}^{3}$ of respirable quartz.

We calculated the likely dust burden in the lungs of patient 2 . In the absence of clearance the human lung burden is simply the accumulated deposited dose in the alveolar region. For respirable particles, the deposition efficiency is about 0.13 . Assuming an average breathing rate of $20 \mathrm{l} / \mathrm{min}$, with the estimated exposure pattern, a final total lung burden of about $4 \mathrm{~g}$ was predicted. At necropsy, the lung burden of quartz was found to be $21 \mathrm{mg} / \mathrm{g}$ dry lung, equivalent to a total lung burden of about $6 \mathrm{~g}$ (assuming a dry lung weight of about $300 \mathrm{~g}$ ). The similarity of these two estimates suggests that the lung clearance of quartz for this patient has been severely impaired before starting his final job working in sandstone, causing retention of almost all of the quartz subsequently inhaled and deposited.

\section{Discussion}

A proportion of inhaled respirable quartz is deposited in the alveolar region of the lung. ${ }^{4}$ Quartz is cytotoxic to alveolar macrophages, leading to impairment of macrophage mediated clearance and damage to the epithelium, with inflammation and translocation of silica particles to the pulmonary interstitium. ${ }^{5}$ Interstitial fibrosis follows prolonged retention of silica in this anatomical location whereas alveolar disruption and oedema can follow acute high exposures. Interstitial fibrosis may be attributed to the stimulation of fibroblast growth by cytokines released from activated interstitial macrophages and alveolar disruption to acute damage to alveolar epithelial cells. In the early stages of exposure, however, after interstitialisation, free and phagocytosed silica particles are readily removed to the lymphatics, and quartz induced damage to this translocation pathway may result subsequently from impaired removal of quartz from the pulmonary region and accentuation of lung toxicity. Animal studies of the retention and clearance of quartz have shown a progressive impairment of clearance starting from a very low burden of quartz $\left(0.1 \mathrm{mg} / \mathrm{g}\right.$ dry lung) ${ }^{6}{ }^{7}$ Oberdörster et al have shown, in a rat model, a total failure of clearance of crystalline silica (in this case, cristobalite) at about $0.3 \mathrm{mg} / \mathrm{g}$ dry lung weight. ${ }^{8}$ As severe impairment of quartz clearance in rodents can be achieved at very low lung burdens, it is reasonable to extrapolate this result to humans.

Our ability to calculate the quartz exposures of our patients has allowed us to shed new light on the pathogenesis of silicosis in humans and to measure the risks relative to exposure concentrations. The difference between the exposures of the two men (fig 2) lay almost entirely in that the older man had had previous low level exposure over 30 years, sufficient to cause eggshell hilar calcification-in other words he had destruction of the hilar nodes by silicotic fibrosis. Thereafter, he and the younger man shared essentially the same very high exposures over about six years, when the older man died of rapidly progressive diffuse silicotic fibrosis. The younger man, who had no previous exposure history, developed only an acute inflammatory reaction in his hilar nodes. These subsequently fibrosed and calcified, at which point early massive fibrosis appeared at his lung apices. This suggests that lymph node fibrosis, by preventing further elimination of dust from the lung, sets the scene for the development of massive fibrosis with continued low dose exposure, or with high exposures, for rapidly progressive silicosis.

A role for the lymph nodes has been suggested previously in coalworkers' massive fibrosis. Seal et al noted the disruption of hilar nodes in miners from south Wales, sometimes associated with rupture of dust laden material into airways and pulmonary vessels. ${ }^{9}$ They suggested that aspiration and embolisation of this matter might be responsible for the secondary nodules of coalworkers' massive fibrosis, but acknowledged that blockage of nodes might afford an alternative or additional explanation. In silicosis the hilar nodes are very much more fibrotic than in coalworkers' pneumoconiosis and it seems, at least in our patients, that the blockage hypothesis is the more likely.

The evidence on which the United Kingdom and other quartz standards are based is epidemiological, and in the hope of finding a safe threshold is largely derived from studies in which the exposures to quartz and overall risks of silicosis have been relatively low. Our findings suggest that the more severe manifestations of silicosis occur when the hilar nodes are destroyed by fibrosis, and that this may follow prolonged exposures to quite low concentrations (estimated to be even less than 0.1 $\mathrm{mg} / \mathrm{m}^{3}$ for 30 years in patient 2 ), or after short exposures to very high concentrations (1.5 $\mathrm{mg} / \mathrm{m}^{3}$ for six to seven years in patient 1 ). With the figures from a detailed study of Ontario miners, ${ }^{10}$ an exposure to $0.1 \mathrm{mg} / \mathrm{m}^{3}$ for 30 years equates to a roughly $1 \%$ risk of category 1 or greater silicosis, agreed by three out of five film readers. This is in keeping with our patient 2 who had no lung (as opposed to lymph node) involvement until he started work on sandstone. Fatal or disabling disease is likely to occur rapidly with exposures over about 1 $\mathrm{mg} / \mathrm{m}^{3}$ in workers with previous low level exposure, but to take a few years longer and be less severe in new recruits to the industry with no previous exposure. This fits with observations made in the few other circumstances where 
severe or fatal silicosis has occurred-in Indian slate workers $\left(2-10 \mathrm{mg} / \mathrm{m}^{3}\right),{ }^{11}{ }^{12}$ Louisiana sandblasters $\left(5 \mathrm{mg} / \mathrm{m}^{3}\right),{ }^{13}$ and Hong Kong jade polishers $\left(0.7 \mathrm{mg} / \mathrm{m}^{3}\right) .^{14}$

The current United Kingdom maximum exposure limit for quartz is $0.3 \mathrm{mg} / \mathrm{m}^{3}$. We think that this concentration inhaled over several years is sufficient to cause fibrosis of hilar lymph nodes, and once this has occurred, further exposure will cause pulmonary silicosis. Indeed, the data of Muir $e t a l^{10}$ indicate a risk of silicosis of International Labour Organisation (ILO) category 1 or greater of about $7 \%$ over a working lifetime at this concentration. The methods of working stone nowadays increasingly involve the use of powered tools which may easily generate concentrations of dust of several $\mathrm{mg} . \mathrm{m}^{-3}$, and if the stone is predominantly quartz such concentrations can be guaranteed eventually to cause severe or even fatal disease.

1 Seaton A, Legge JS, Henderson J, et al. Accelerated silicosis in Scottish stonemasons. Lancet 1991;337:341-4.

2 Health and Safety Executive. Occupational exposure limit 1997. Norwich: HMSO, 1997. (Guidance note EH40/97.)

3 Cherrie JW, Schneider T, Spankie S, et al. A new method for structured subjective assessments of past concentrations. Occup Hyg 1996;3:75-83.
4 Heyder J, Gebhart J, Rudolf G, et al. Deposition of particles in the human respiratory tract in the size range $0.005-15$ mm. F Aerosol Sci 1986;17:811-25.

5 Donaldson K, Bolton RE, Jones AD, et al. Kinetics of the bronchoalveolar leukocyte response in rats during exposure to equal airborne mass concentration of quartz, chrysotile asbestos or titanium dioxide. Thorax 1988;43:159-62.

6 Vincent JH, Jones AD, Johnston AM, et al. Accumulation of inhaled mineral dust in the lungs and associated lymph nodes: implications for exposure and dose in occupational lung disease. Ann Occup Hyg 1987;31:375-93.

7 Tran CL, Jones AD, Donaldson K. Mathematical model of phagocytosis and inflammation after the inhalation of quartz at different concentrations. Scand $\mathcal{F}$ Work Environ Health 1995;21(suppl 2):50-4.

8 Oberdörster G, Cox G, Gelein G. Intratracheal instillation versus intratracheal inhalation of tracer particles for measuring lung clearance function. Exp Lung Res 1997;23:1734

9 Seal RME, Cockcroft A, Kung I, et al. Central lymph node changes and progressive massive fibrosis in coalworkers. Thorax 1986;41:531-7.

10 Muir DCF, Julian JA, Shannon HS, et al. Silica exposure and silicosis among Ontario hardrock miners: III. Analysis and risk estimates. Am F Ind Med 1989;16:29-43.

11 Saiyed HN, Parikh DJ, Ghodasara NB, et al. Silicosis in slate pencil workers: I. An environmental and medical study. $A m$ f Ind Med 1985;8:127-33.

12 Saiyed HN, Chatterjee BB. Rapid progression of silicosis in slate pencil workers: II. A follow up study. $A m \mathcal{F}$ Ind Med 1985;8:135-42.

13 Samini B, Ziskind M, Weill $\mathrm{H}$. The relation of silica dust to accelerated silicosis. Ecotoxicol Environ Safety 1978;1:42936

$14 \mathrm{Ng}$ TP, Allan WGL, Tsin TW, et al. Silicosis in jade workers. Br f Ind Med 1985;42:761-4. 